\title{
Analytics as a service : Framework to Assess Whether There Is any Winning Value Proposition
}

\author{
Dr. Gadang Ramantoko \\ Schools Of Economics and Business \\ Telkom University \\ Bandung, Indonesia \\ gadangramantoko@telkomuniversity.ac.id
}

\author{
Tri Widarmanti, S.MB \\ Schools Of Economics and Business \\ Telkom University \\ Bandung, Indonesia \\ triwidarmanti@telkomuniversity.ac.id
}

\begin{abstract}
Analytics which started as business intelligence two decades ago has turned the firm into a data driven company. Analytic metamorphoses itself into a service where the term Analytic-a-a-Service (AaaS) comes from. Analytics that are provided by consultants to a firm - to solve analytics need of the firm with their data - in a state-of-theart manner shows up into a business model. AaaS value proposition serves clients with analytics on demand, in which the clients pay for the use of analytical solutions as a service from cloud service providers. The value propositions converge into three groups of characteristics: hosting, full stack, and expose. While the AaaS is evolving into a more and more commoditized service, it poses an intriguing question whether any of the three value proposition characterizing the business model will come out a winner. This article brings out the spectrum of the offering with regard to Aas: how they are offered, and proposes a framework where a company can use it to assess the winning business model of the said services.
\end{abstract}

Keywords-Analytics; Analytic-as-a-Service; Big data; Framework; Value proposition; Business Model.

\section{INTRODUCTION : THE MEANING OF ANALYTICS}

A firm learns through its data. Data analytics in a firm have been existing since managers introduced information support system in business. While analytics in business is understandable, the definition it still not coming into a convergent agreement.

\section{A. Analytics : Noun or adjective?}

Analytics according to many dictionaries is considered adjective. The meaning of analytic according to MerriemWebster - the meaning closest to our research context - is : treated or treatable by using the method of algebra and calculus. [1] Meanwhile, Zhu defines analytics as "the use of data, information technology, statistical analysis, quantitative methods, and mathematical or computer-based models to help managers gain improved insight about their business operations and make better, fact-based decisions. [2]

Wikipedia defines analytic as the discovery and communication of meaningful patterns in data.[3] Sun et.al define analytic as the use of data, information technology, statistical analysis, quantitative methods and mathematical or computer-based models to help managers gain improved insight about their business operation and make it better. [4] It seems as if the definition of analytic is evolving from adjective to noun.

The definitions by Zhu's, Wikipedia's, and Sun's fall into the noun category. The meaning of analytic (adjective) and data-analytic (noun) becomes interchangeable.

\section{B. Analytics is a process of data analysis}

The vocabulary reference for data analytic today switch from the well established dictionary such as Merriam-Webster to IT companies such as IBM, Oracle and others and to technology universities such as MIT. From the University, Liberatore and Luo define analytics as "a process of transforming data into action through analysis and insight in the context of organizational decision making a problem solving" [5]. Data analytic -according to IBM - is associated with the use of advanced analytic techniques against very large data. When data is associated with big data, analytic techniques means what is used against structured/unstructured and streaming/batch, and different sizes from terabytes to zettabytes[6] .

Cooper and Adam define analytics as the process of developing actionable insights through problem definition and the application of statistical models and analysis against existing and/or simulated future data [7]. The meaning of "actionable" is that analytics is more concerned with practical actions rather than theoretical description or just a reporting activity. The conclusion derived from the analytics process should lead to rational decisions. The result of analytics process will act as a necessary warrant to the action. The process will provide a level of clarity and lead to actionable insight victorious in pursuing opportunity.

Analytics is a process of discovery of meaningful pattern by studying materials involving a breaking of a complex topic, data, or materials into smaller units. The process will lead to: gaining a better understanding, researching potential trends, analyzing the effect of certain decisions or events, or evaluating the performance of a given tool scenario. [8] [9] All of these have the meaning of improving business by gaining knowledge which can be used to make improvements or change.

Analytics' process involves: [9] 
1. It uses various methods of statistic, technology, queries, and research to predict, quantify and evaluate performance.

2. It involves complex, extensive and embedded computation that is applied to data, to evaluate, predict, describe, and improve business performance.

3. It uses models, computer science, algorithm, statistical methods, behavioral science, demographic, geographic, and socio factor.

4. Visualization tools (patterns, dashboard, maps, chart) are used to communicate outcomes.

5. Dimensionalizing the data is used with core current information and increased resources, empowering more constructive and more knowledgeable decision making process.

It is a common agreement today that analytics is divided into at least three categories: descriptive - using data to understand past and present performance, predictive - analyze past performance to predict the future, prescriptive - focused primarily on optimization (identification of best alternatives to minimize or maximize desired objectives). Statistics plays a role in all the three categories as following: descriptive statistical measures, probabilities, distributions, sampling, and estimation; predictive - regression, forecasting, simulation, and risk analysis; prescriptive - linear, non-linear, integer, optimization. [2] The three divisions of analytics constitute the so called analytics maturity levels.

\section{Analytic-as- a-Service}

Analytic which started as business intelligence two decades ago has turned firms into data driven companies. Businesses are increasingly flattening decision-making hierarchies to empower more knowledge workers and become more responsive to customers. Analytics metamorphoses itself into a service from which the term AaaS came from.

A firm in need of analytic with their data may request consultants to provide a state-of-the-art analytics services. The services may cover the areas of Predictive Analytics, CRM Analytics, Conjoint Analytics, Market Research, Marketing Mix Modeling, Customer Segmentation, Data Visualization and Big Data. This service is basically outsourcing of all analytics activities used to be done internally in an organization.

The requirement to outsource analytics may range from small and mid-size clients to large, including Fortune 500 companies, in a number of sectors like $\mathrm{CPG}$, retail, financial services, media/entertainment, technology, healthcare, automobiles and consulting [10]. The motive to outsource is then to get smart and get innovative in ways they could never do before.

\section{Perspective in AaaS}

Open Data: perspective analytic outsourcing has led us to the era of open data. Organizations are increasingly expected to unlock data and develop new insights through advanced analytics that can be shared across the company and with suppliers, customers and partners. Helping people make better decisions is now deemed essential to compete effectively. Satisfying demand and updated business intelligence, selfservice capabilities, real-time and machine-to-machine analytics fall to the analysis of IT departments that are already facing tight budget constraints, lack of infrastructure and a shortage of people with the right skills. IT departments are challenged to overcome the reporting a backlog and forecast the needs that have accumulated since the business intelligence system hasn't been able to change with the business demand or adapt to the new nature of the data very varied and found everywhere.

Real time insight: it takes a different approach to the provision of insight. Delivery timely information must be made, information made new and up to date, flexible business model must include governance of the business involved, the integration of traditional, open technology and self-service, third-party managed data science and visualization services, plus a variety of models of employment. The fact is that the traditional structured data-analytics in some industries is certainly ahead of others in the race to understand their business and customer relationship [11].

Analytics capability is a competitive advantage : provider AaaS positioned to help businesses uses customized analytics solutions tailored to accurately assess the current business environment and predict future trends for competitive advantage [12]. Organizations need to know what is happening now, what might happen next, and what actions should be taken to obtain optimal results; analytic can help companies gain insight for customers and operations while reducing management overhead - though not eliminating it..

Analytics is overvalued: MITSloan Management Review, in collaboration with IBM Institute for Business Value (2011), conducted a survey of over 3000 business executives, managers, and analysts from organizations located around the world. The survey results show top-performing organizations use analytics five times more often than lower performers, a widespread belief of analytics over value. Half of the respondents said that the improvement of information and analytics was a priority in their organization, and more than one in five said they were under intense or significant pressure to adopt advanced information and analytic approaches; they also agreed that their organization has more data that can be used effectively. Organization leaders want analytics to exploit their growing data and computational power. [13]

Deavenport and Harris state that analytics is the secret weapon to battle [14]. Value proposition of "as-a-service" eliminated manual IT tasks that have hampered business users from gaining access to technology services, while IT is used to ensure the enforcement of security, privacy, and compliance controls. Analytics serves as a service empowering knowledge workers by giving them personal accesses to centrally managed information data sets[15]. In this study, the authors seek to understand the spectrum of the offering with regard to AaaS (AaaS), how they make offers, and propose a framework where a company can use to assess the winning business model of the said services. 


\section{AAAS: VALUE PROPOSITION}

Today's businesses are operating in a highly competitive and complex environment where new technologies, products and services are creating new industries, changing customer behaviors and driving new competition. In this environment, organizational decisions need to be based on accurate and insightful data. Business needs an advanced analytics capabilities coupled with its vast industry experience, is positioned to help businesses use customized analytics solutions to accurately assess the current business environment and predict future trends for competitive advantages Kesalahan! Sumber referensi tidak ditemukan.. When dealing with traditional structured data-analytics, in the race to understand their business and customer relationship, some industries are definitely ahead of others.

In manufacturing industries, for example, reducing cost through manufacturing, increasing employee productivity, and utilizing place and time, is prevalent. By introducing valueadd-services to a product, more and more data are being created in a gold mine of data but the financial benefits are yet to be seen. Selecting every information from every point in the manufacturing plot for the entire global operation and processing the data is a daunting task. AaaS, through package data analytic platform, helps to maximize efficiency and create a win-win situation in the industry.

Managing and gaining insights from the produced data are a challenge and key to competitive advantages. An organization willing to use analytics technology frequently acquires expensive software license, employs large computing infrastructure, and pays for consulting hours of analysts who work with organizations to better understand its business, organize its data and integrate it for analytics [16].This joint effort of organization and analysts often aims to help the organization understand its customer's needs, behaviors, and future demands for new products or marketing strategies [18]. Making sense of data extracting non obvious patterns and using these patterns to predict the future behavior are also the topic. Knowledge Discovery in Data (KDD)[16]. Davenport and Harris in their book also describe how many organizations are using analytics strategically to make better decisions and improve customers and shareholder values [14].

\section{AAAS IN BIG DATA}

Big Data conventionally is defined by 4Vs: Volume, Velocity, Variety, and Veracity [19] [20].

Volume describes lots of data involved. To put this into context, forty zettabytes will be created by 2020 , an increase of $300 \%$ from that in $2005 ; 2.5$ quintillion bytes are created each day; most company will have at least 100 terra bytes.

Velocity concerns the analysis of streaming data. Velocity occurs where the data is time-sensitive and needs to be processed and stored quickly. One example is the real-time profiling of internet display adverts that is customized according to your usage patterns. To put it into context, the New York Exchange captures one terra bytes of trade information during each trading session; modern cars have closed to 100 censors that monitor items such as fuel level and tire pressure.

Variety deals with different forms of data. Variety covers the various forms that data can take, from neatly-structured tabular data, to unstructured data containing items such as images, emails, spreadsheets, social media conversations and streaming media. Currently, there is no universally accepted "one-size-fits-all" approach to handling this data variety. To put it into context, as of 2011 global size of data in healthcare was estimated to be 150 Exabyte's; 30 billion pieces of contents are shared on Facebook every month; 400 tweets are sent per day by about 200 million active users.

Veracity describes the uncertainty of data. In big data phenomenon, data is abundant, but the accuracy, the quality, and the source are not exactly trustworthy.

Other initiatives add four more Vs: validity, value, variability and visibility to describe Big Data.

Big data have increased the demand for information management specialists in that Software AG, Oracle Corporation, IBM, Microsoft, SAP, EMC, HP and Dell have spent more than $\$ 15$ billion on software firms specializing in data management and analytics. In 2010, this industry was worth more than $\$ 100$ billion and was growing at almost 10 percent a year, about twice as fast as the software business as a whole[21]. Big data is a buzzword and a "vague term", but at the same time an "obsession" with entrepreneurs, consultants, scientists and the media [22].

Analytic-as-a-Service, through cloud-services, provides tools that customer can use to build their Big Data analytics solution to the Cloud. Models for delivering analytics capabilities as a service on a Cloud have been discussed by Sun et al[23]. Some of the potential business models proposed on their work include:

1. Hosting customer analytics jobs in a shared platform: suitable for an enterprise or organization that has multiple analytics departments. Traditionally, these departments have to develop their own analytics solutions and maintain their own clusters. With a shared platform they can upload their solutions to execute on a shared infrastructure, and therefore reducing operation and maintenance costs. As discussed beforehand, techniques have been proposed for resource allocations and scheduling of Big Data analytics tasks on the Cloud.

2. A full stack designed to provide customers with end-toend solutions: appropriate for companies that do not have expertise on analysis. In this model, analytical service providers publish domain specific analytical stream templates as services. The provider is responsible for hosting the software stack and managing the resources necessary to perform the analyses. Customers who subscribe to the services just need to upload their data, configure the templates, receive models, and perform the proper model scoring.

3. Expose analytics models as hosted services: analytics capabilities are hosted on the Cloud and exposed to customers as services. This model is proposed to companies that do not have enough data to make good 
predictions. Providers upload their models, which are consumed by customers via scoring services provided by the Cloud.

Krishna and Varma envision two types of service for Cloud analytics[24]: (i) AaaS (AaaS), where analytics is provided to clients on demand and they can pick the solutions required for their purposes; and (ii) Model as a Service (MaaS) where models are offered as building blocks for analytics solutions.

To characterize AaaS in big data further, there are five keys of as-s-service characteristics - as proposed by JISC CETIS Cloud Computing - Kesalahan! Sumber referensi tidak ditemukan.:

1. Rapid Elasticity: service capabilities can be rapidly and elastically provisioned to quickly scale up and rapidly release to quickly scale down.

2. Ubiquitous network access: service capabilities are available over the network and accessed through standard mechanisms that promote use by heterogeneous thin or thick client platforms (for example: mobile phone and laptop etc).

3. Pay per use: service capabilities are charged using a metered, fee for service, or advertising base on billing model to promote optimization of resource use.

4. On-Demand Self-Service: a consumer can unilaterally provision computing capabilities, such as server time and network storage, as needed, without requiring human interactions with each service's provider.

5. Location independent data centers: the provider's computing resources are usually pooled to serve all consumers using a multi tenant model, with different physical and virtual resources dynamically assigned and reassigned according to consumer demand.

These five key characteristics are commonly referred to as-aService value proposition. It follows that this common value proposition is an advantage from the perspective of the service due to the latest underlining technology life cycle.

Marten Hawksey (2012) proposed a suggestion on AaaS (Aaas): the capability provided to the customer is to use the providers applications running on a cloud infrastructure to extract "actionable insights through problem definition and the application of statistical models and analysis against existing and/or simulated future data". Examples include application specific solution like Google analytics and more general offering like Amazon AWS.Kesalahan! Sumber referensi tidak ditemukan. Table 1 below summarizes the value propositions of AaaS from various web sources. It is shown that the majority of players in AaaS offer the three categories of value: hosting, full stack and expose. Meanwhile, Table 1 suspects that AaaS is evolving into more and more commoditized service; an intriguing question has arisen: on what basis then will a company select an AaaS provider other than that based on price criteria? Among the three value propositions, there is going to be a prevailing category, which one answers most of the problem of analytics within a firm? A firm then needs a framework to use a basis for selection. The authors propose a working framework in the following paragraph.

TABLE I. SUMMARY OF AAAS BIG DATA VALUE PROPOSITION*)

\begin{tabular}{|c|c|c|c|}
\hline \multirow[b]{2}{*}{ Player } & \multicolumn{3}{|c|}{ Category } \\
\hline & $\begin{array}{c}\text { Hosting } \\
\text { customer } \\
\text { analytics jobs } \\
\text { in a shared } \\
\text { platform }\end{array}$ & $\begin{array}{c}\text { A full stack } \\
\text { designed to provide } \\
\text { customers with end- } \\
\text { to-end solutions }\end{array}$ & $\begin{array}{c}\text { Expose } \\
\text { analytics } \\
\text { models as } \\
\text { hosted } \\
\text { services }\end{array}$ \\
\hline 1010data & $\sqrt{ }$ & - & - \\
\hline Actian & $\sqrt{ }$ & $\sqrt{ }$ & $\sqrt{ }$ \\
\hline $\begin{array}{c}\text { Amazon } \\
\text { Web Service }\end{array}$ & $\sqrt{ }$ & $\sqrt{ }$ & $\sqrt{ }$ \\
\hline Cloudera & $\sqrt{ }$ & $\sqrt{ }$ & $\sqrt{ }$ \\
\hline HP & $\sqrt{ }$ & $\sqrt{ }$ & - \\
\hline Hortonworks & $\sqrt{ }$ & $\sqrt{ }$ & $\sqrt{ }$ \\
\hline IBM analytic & $\sqrt{ }$ & $\sqrt{ }$ & $\sqrt{ }$ \\
\hline Infobright & $\sqrt{ }$ & $\sqrt{ }$ & - \\
\hline $\begin{array}{l}\text { Kognito } \\
\text { Analytic } \\
\text { service }\end{array}$ & $\sqrt{ }$ & $\sqrt{ }$ & $\sqrt{ }$ \\
\hline MapR & - & $\sqrt{ }$ & $\sqrt{ }$ \\
\hline Microsoft & $\sqrt{ }$ & $\sqrt{ }$ & - \\
\hline Oracle & & $\sqrt{ }$ & $\sqrt{ }$ \\
\hline Pivotal & $\sqrt{ }$ & $\sqrt{ }$ & $\sqrt{ }$ \\
\hline SAP & - & $\sqrt{ }$ & $\sqrt{ }$ \\
\hline Teradata & $\sqrt{ }$ & $\sqrt{ }$ & - \\
\hline
\end{tabular}

\section{FRAMEWORK FOR ASSESMENT OF BUSINESS MODEL}

Alexander Osterwalder and Pigneur proposed a twofold assessment tool which represents a SWOT for the entire model and then additionally a SWOT for each building block of the model[26].To compare several value propositions using this framework, one needs to do a lot of SWOTs while comparing each of them which, despite a lot of work, doubtfully will provide necessary insights to sustainability of the model. A more direct approach to evaluating values is as proposed by Pater [27] who proposed a framework for the total value proposition that can be applied to a renewable electricity generation, distributed generation technology, energy efficiency, and clean fuels. The wisdom behind the proposition is that while millions of dollars has been invested in these technologies, deployment has proceeded at a much slower rate than anticipated, primarily due to the fact that investors do not believe that they can monetize the full suite of benefits that these technologies present. The background condition is somewhat similar to the condition of AaaS in Big data technology whose value is calculated using value chain approaches. However, the framework approach using value chain is too simple for the case of an ecosystem that is as complex as big data's. Pater's conceptual (value chain) work can be further developed by integrating it into PARTS conceptual value network model as proposed by Brandenburg [27]. Integrating Pater and Brandenburg will help assess the AaaS ecosystem. The objective of the value network is then to answer the following two questions into single firm as a result of the operation in a specific AaaS ecosystem:

1. How much is profit created for oneself by one's own participation versus by others' participation. 
2. How much is the profit for others by own participation: if others' value add increases, is it good or bad; win-win or win-lose situation?

A more practical method in assessing a business model has been summarized as composed of several alternate factors [28] as follows.

1. Uniqueness or novelty; this defines what sets the business model apart from others of its kind in the market.

2. The future likelihood of making profits from the business model or the business model's ability to remain unique from the rest.

3. Comprehensiveness or how thoroughly it covers the entirety of the scope it is aimed towards.

4. Inimitability; how difficult it is for others to emulate the same model due to the unique factors that make it up.

5. Robustness or how well the business model stands various tests and still remains viable.

6. Sustainability or the business model has the ability to continue at a consistent rate or level.

George Herman, Thomas G. Apel, and Stephanie L. Woerner in their study proved that some business models perform better than others [29]. Herman et.al. argued that the heart of any business is : what rights are being sold and came into four categories of rights sold and amount of transformation of assets?

1. A creator buys raw materials or components from suppliers and then transforms or assembles them to create a product sold to buyers. This is the predominant business model in manufacturing.

2. A distributor buys a product and resells essentially the same product to someone else. The distributor usually provides additional values by, for example, transporting or repackaging the product, or by providing customer service. This business model is ubiquitous in wholesale and retail trade.

3. A landlord sells the right to use, but not own, an asset for a specified period of time. This asset rights model highlights a deep similarity among superficially different kinds of business: all these businesses, in very different industries, sell the right to make temporary use of their assets.

4. A broker facilitates sales by matching potential buyers and sellers. The broker receives a fee (or commission) from the buyer, the seller, or both. This business model is common in real estate brokerage, stock brokerage, and insurance brokerage.

Herman et.al. further classify the assets being involved in the business into four categories: financial, physical, intangible and human as shown in Figure 1.

\begin{tabular}{|c|c|c|c|c|c|}
\hline & & \multicolumn{4}{|c|}{ What type of asset is involved } \\
\hline & & Financial & Physical & Intangible & Human \\
\hline \multirow{4}{*}{$\begin{array}{l}\text { What } \\
\text { rights } \\
\text { are } \\
\text { being } \\
\text { sold? }\end{array}$} & Creator & $\begin{array}{c}\text { Entrepren } \\
\text { eur }\end{array}$ & $\begin{array}{c}\text { Manufactu } \\
\text { re }\end{array}$ & Inventor & $\begin{array}{l}\text { Human } \\
\text { Creator }\end{array}$ \\
\hline & $\begin{array}{c}\text { Distribu } \\
\text { tor }\end{array}$ & $\begin{array}{c}\text { Financial } \\
\text { Trader }\end{array}$ & $\begin{array}{c}\text { Wholesaler } \\
/ \\
\text { Retailer }\end{array}$ & IP Trader & $\begin{array}{c}\text { Human } \\
\text { Distribut } \\
\text { or }\end{array}$ \\
\hline & $\begin{array}{c}\text { Landlor } \\
\text { d }\end{array}$ & $\begin{array}{l}\text { Financial } \\
\text { Landlord }\end{array}$ & $\begin{array}{l}\text { Physical } \\
\text { Landlord }\end{array}$ & $\begin{array}{c}\text { Intellectual } \\
\text { Landlord }\end{array}$ & $\begin{array}{c}\text { Contract } \\
\text { or }\end{array}$ \\
\hline & Broker & $\begin{array}{c}\text { Financial } \\
\text { Broker }\end{array}$ & $\begin{array}{l}\text { Physical } \\
\text { Broker }\end{array}$ & IP Broker & $\begin{array}{c}\text { HR } \\
\text { Broker }\end{array}$ \\
\hline
\end{tabular}

Figure 1. Herman's sixteen business model. [30]

In the case where focus is on value proposition, McGlaughlin showed that the force of a value proposition can be measured by four essential elements of the offer in the tools, whose examples are shown in Figure 2. [30][31] The tools are used to measure the following components :

a. Appeal - How much do I desire this offer?

b. Exclusivity - Where else can I get this offer?

c. Credibility - Can I trust your claims?

d. Clarity - What are you actually offering?

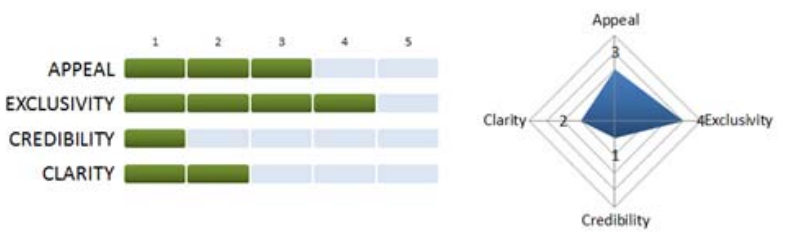

Figure 2. Audience Submission : Example application of tool. [30]

Integrating several factors described above, the framework to asses AaaS business model from the perspective of value proposition alone is established. Figure 3 shows the framework.

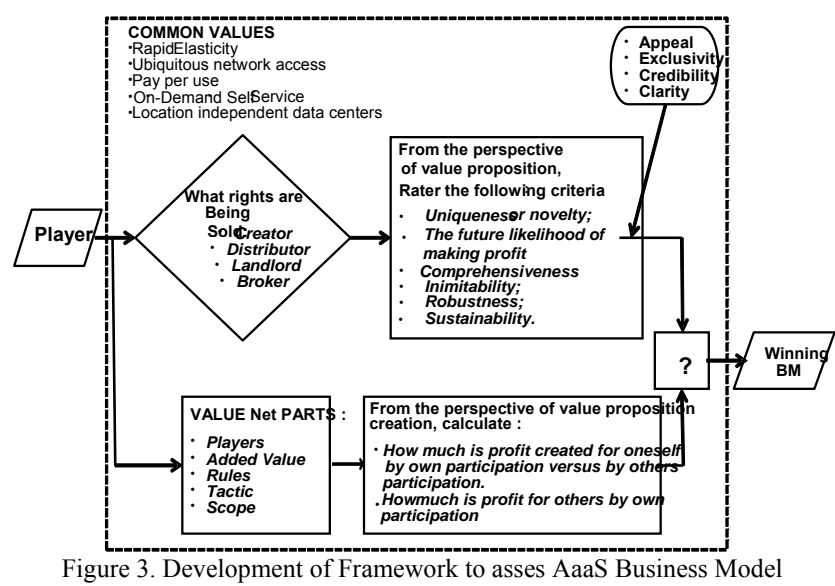

The framework starts with selecting specific players and the specific value category to be studied: whether it is hosting, 
full stack, or expose. The next step is to determine what area of business is to be served. Following Herman classification, there is one, out of sixteen areas, to be selected. The next step is to rate the value proposition according to the criteria of alternate factors. In rating them, the factors will be tested using McGlaughlin's measurement scale. For instance, when rating uniqueness of a business model, it is tested from the perspective of value proposition, whether it calls for a scaling of: Appeal, Exclusivity, Credibility, and Clarity. However, since assessment of value proposition alone will not give the whole picture of a business model, a second stream of assessment is added. This second stream follows Brandenburg's criteria of industry competition: PARTS. The assessment needs the total value added in the ecosystem involved in the value creation to be calculated. It is really not an easy task, especially when the player in question is not a public company. The value proposition assessment and added value assessment then need to be combined to provide a predictive performance of a player, in a specific area of business for a specific AaaS value proposition. In this case, a competitive landscape can be drawn.

\section{CONCLUSION \& FURTHER RESEARCH}

This paper mainly discusses value proposition of AaaS and the proposed framework to answer the research question whether there is a winning business model, viewed from the perspective of value proposition. While the variety of value proposition has been tabulated, describing approaches proposed by several players, for the purpose of getting to any concrete conclusion, the framework has been proposed. The next logical step following the proposition is to test whether the framework is operational.

It is interesting to investigate the case reported by Analytics Business Process Service (BPS) - service provider landscape with PEAX Matrix Assessment 2015 using the proposed framework. The report identified several key differentiators between service providers and recognized "leaders" from their demonstrated excellence in market success and delivery capability[32]. From a market success perspective, these "leaders" achieved a significant lead over peers in term of analytic Business Process Service revenue and Client Base. These providers also have the early-mover advantage and have considerable scale across the analytics value chain, including predictive and prescriptive analytics. The success being "leader" is based on company's ability to deliver valuable insight supported by technology analytics integration, IP-based, industry specific analytics model, proprietary analytics platform, highly skilled team of data scientists, exclusive analytics labs and analytics Center of Excellence. Also, they have strong delivery capabilities comprehensive solution set and industry thought leadership in serving its clients.

The next step following testing of the framework is to use it for measurement on the field. It will take a while before the question gets the answer.

\section{References}

[1] Analytics (2015). Retrieved october 2, 2015 from http://i.word.com/idictionary/analytic

[2] Zue, Phearl. (2015, January). Analytics vs. Statistics. Retrieved from http://futureofcio.blogspot.co.id/2015/01/analytics-vs-statistics.html

[3] Analytics. (n.d.). Retrieved October 20, 2015 from the Analytics Wiki: https://en.m.wikipedia.org/wiki/analytics

[4] X. Sun., B. Gao., Y. Zhang., W. An., H. Cao., C. Guo., W. Sun., (2011). Towards Delivering Analytical Solutions in Cloud: Business Models and Technical Challenges. Proceedings of the IEEE 8th International Conference on e-Business Engineering (ICEBE 2011), IEEE Computer Society, Washington, USA, pp. 347-351.

[5] Liberatore, Matthew J., Weng, Hong Luo.(2010). The analytics movement: Implication of operations research. Interface 40, No 4 (JulyAugust): 313-324.

[6] What is Big Data Analytics ?(2015). Retrieved October 20, 2015 from http/www-01.ibm.com/software/data/infosphere/hadoop/what-is-bigdata-analytics.html

[7] Cooper, Adam., (2012). What is Analytics? Definition and Essential Characteristics, CETIS Analytics Series Volume 1, No 5, pp.3

[8] Analytics.(n.d). Retrieved October 23, 2015 from businessdictionary: http://www.businessdictionary.com/definition/analytics.html

[9] Analytics as a Service (AaaS $\square$ ) (2015). Retrieved October 25, 2015 from http://www.gsa.gov/portal/content/226367

[10] List of Companies in India(2015). Retrieved October 26, 2015 form: http://analyticsindiamag.com/big-data/List of analytics companies in India.html

[11] Analytics as a service (2015). Retrieved October 26, 2015 from http://www.csc.com/big_data/offerings/82345/117345analytics_as_a_service

[12] TCS Recognized as a 'Leader' in Analytics Business Process Services (BPS) by Everest Group (2015). Retrieved October 26, 2015 from http://www.tcs.com/news_events/press_releases/Pages/TCS-LeaderAnalytics-BPS-Everest-Group.aspx

[13] Lavalle, Steve., Lesser, Eric., Shockley, Rebecca., Hopkins, Michael s., Kruschwitz, Nina. (2011), Big Data, Analytics and the Path From Insights to Value, MITSloan Management Review Vol.52 No.2

[14] Davenport, Thomas H., and Jeanne G., Harris. (2007). Competing on Analytics: The New Science of Winning. Boston: Harvard Business School Press

[15] Mathiprakasam., Murthy. (2014, Sept 26). The Road To Analytics As a Service. Retrieved October 26, 2015 from http://www.forbes.com/sites/oracle/2014/09/26/the-road-to-AaaS

[16] TCS Recognized as a 'Leader' in Analytics Business Process Services (BPS) by Everest Group (2015). Retrieved October 26, 2015 from http://www.tcs.com/news_events/press_releases/Pages/TCS-LeaderAnalytics-BPS-Everest-Group.aspx

[17] Fayyad, Usama., Piatetsky Shapiro, G., Smyth, Padhraic., (1996) The KDD Process for Extracting Useful Knowledge from Volumes of Data, Communications of the ACM 39 (11) 27-34.

[18] Assuncao, D. Marcos., Chalheirosb, Rodrigo N., Bianchic, Silvia., Netto, Marco A. S., Buyya, Rajkumar., (2014). Big Data Computing and Clouds, Trens and Future Directions, Journal of parallel and Distributed Computing, August 25, 2014 arVix:13124722v2

[19] The Four V's of Big Data (2015). Retrieved from http://www.ibmbigdatahub.com/sites/default/files/infographic_file/4-Vsof-big-data.jpg

[20] Big Data (2015). Retrieve October 27, 2015 from https://en.wikipedia.org/wiki/Big_data

[21] Data, data everywhere, The Economist (2010, February 25). Retrieved October 26, 2015 from http://www.economist.com/node/15557443

[22] Harford, Tim (2014, March 28). "Big data: are we making a big mistake?".Financial Times. Financial Times. Retrieved October 27, 2015 from http://www.ft.com/cms/s/2/21a6e7d8-b479-11e3-a09a00144feabdc $0 . h t m l$

[23] 'Big Data' has Big Potential to Improve Americans' Lives, Increase Economic Opportunities (2013, April 24). Retrieve October 27, 2015 
from https://science.house.gov/news/press-releases/big-data-has-bigpotential-improve-americans-lives-increase-economic.

[24] P. R. Krishna., K. I. Varma.(2012). Cloud Analytics: A Path Towards Next Generation Affordable BI, White paper, Infosys

[25] Hawksey, Martin. (2015, November 3) Google Analytics for Learning Analytics - Session for RMIT University. Retrieved October 26, 2015 from https://mashe.hawksey.info

[26] Alexander Osterwalder and Pigneur, Business Model Generation: A Handbook for Visionaries, Game Changers, and Challengers, ISBN: 978-0-470-87641-1, June 2010

[27] J.E. Pater, A Framework for Evaluating the Total Value Proposition of Clean Energy Technologies, Technical Report, NREL/TP-620-38597, February 2006.

[28] Entrepreneurial Insight, Business model generation, How to Assess the Quality of your Business Model, March 31, 2015, Anastasia.

[29] Malone, Thomas W., Weill, Peter., Lai, Richard K., D’Urso, Victoria T., George, Herman., Apel.G.,Thomas, Woerner.L.,Stephanie (2006). Do
Some Business Models Perform Better than Others?, MIT, May 18, 2006, Working Paper 4615-06

[30] Bortone, Brad (2011). Marketing Optimization, Measuring the potential force of your value proposition, September 26th, 2011.

[31] Bortone, Brad (2011, September 26). Marketing Optimization: Measuring the potential force of your value proposition. Retrieved $\begin{array}{llll}\text { October } & 4 & \text {, } & \end{array}$ http://www.marketingexperiments.com/blog/analyticstesting/marketing-optimization-measuring-the-potential-force-of-yourvalue-proposition.html

[32] Gupta,Vishal., Jain,Anupam., Khandelwal, Vishnu., Ranjan, Rajesh. 2015). Cyril Thomas Analytics Business Process Services (BPS) Service Provider Landscape with PEAK Matrix ${ }^{\mathrm{TM}}$ Assessment 2015. Retrieved from https://research.everestgrp.com/Product/EGR-2015-10R-1371/Analytics-Business-Process-Services-BPS-Service-ProviderLand 2015 